\title{
Concordance for changes in allergic asthma domain variables after short-term corticosteroid therapy
}

\author{
Philip E. Silkoff ${ }^{1 *}$ (D, Mark Sarno², Solomon Ssenyange ${ }^{3}$, Vivek Balasubramanyam³ ${ }^{3}$ Brian Awabdy $^{3}$ and Ryan Leard ${ }^{3}$
}

\begin{abstract}
Background: Asthma is a complex syndrome with multiple domains including symptoms, lung function, asthma control, and airway inflammation. A study of Fenom $\mathrm{PRO}^{\mathrm{TM}}$, a novel monitor for exhaled nitric oxide (FeNO), provided an opportunity to look at concordance/discordance (C/D) for changes in multiple asthma domains over a 2-week period after corticosteroid therapy.

Methods: Non-steroid-treated adults and children with uncontrolled asthma had asthma domain measures, (FeNO), forced expired volume in $1 \mathrm{~s}\left(\mathrm{FEV}_{1}\right)$, the 6-item Asthma Control Questionnaire scores (ACQ6), and daily asthma symptoms, assessed before and after a 2-week course of corticosteroids. Asthma symptoms were assessed using a custom novel twice-daily symptom scale (ASX). C/D bidirectional changes in all domains were calculated around both the zero point, and around the minimal important difference (MID) in relevant subjects.

Results: There was a highly significant fall in mean FeNO of $51.7 \%$ over 2 weeks $(p<0.0001)$ accompanied by significant improvements in mean $\mathrm{FEV}_{1}, \mathrm{ACQ} 6$ and ASX scores. However, C/D between individual domains varied considerably between subjects. The C/D between parameters for any change around zero for the combined adults and pediatric population was best for FeNO and ACQ6, 79.3/20.7\% while FEV 1 was more discordant than other parameters in general. When considering changes around the minimal important difference (MID) in a subset, the level of concordance increased in general, with FeNO and ACQ6 demonstrating a C/D of 93.5/6.6\%.
\end{abstract}

Conclusion: This data demonstrates that the concordance between changes in the asthma domains is often substantially less than $100 \%$. Reasons for this may include different time courses for change of the separate domains, the degree of abnormality for each domain at baseline, as well as intrinsic limitations of each parameter.

Keywords: Asthma, Exhaled, Nitric, Oxide, Domains, Concordance, Corticosteroids

\section{Background}

Asthma is a complex syndrome characterized by episodic and chronic symptoms e.g. wheezing, cough, chest tightness and dyspnea, as well as periodic exacerbations which may require short courses of corticosteroids. The asthma syndrome can be regarded as a constellation of domains including symptoms with inherent subjectivity,

\footnotetext{
* Correspondence: philsilkoff@gmail.com

${ }^{1}$ Philadelphia, USA

Full list of author information is available at the end of the article
}

lung function e.g. the forced expired volume in one second $\left(\mathrm{FEV}_{1}\right)$, airway inflammation commonly assessed by exhaled nitric oxide (FeNO), and asthma control as assessed by the asthma control questionnaire (ACQ), all of which may be disturbed to different degrees in an individual subject.

Of interest, dynamic changes in asthma domains, either spontaneous over time or as a result of therapeutic intervention e.g. with corticosteroids in these domains may not be concordant. For example, poor perceivers 
can experience declines in lung function without any increase in accompanying symptoms.

A recent study was performed to fufill US regulatory requirements [1] for clearing a novel FeNO monitor Fenom Pro ${ }^{\text {tu}}$. The clinical precision, accuracy and comparison to NIOX VERO ${ }^{\circ}$, a commonly used FeNO monitor was recently reported [2]. Adults and children with uncontrolled asthma were treated with corticosteroids over a 2-week period. This study provided an opportunity to evaluate short-term concordance/discordance $(\mathrm{C} /$ D) between asthma domains, namely day and nighttime symptoms, $\mathrm{FEV}_{1}$, asthma control via the 6-item ACQ6, and airway inflammation using FeNO which is the focus of this report.

\section{Methods}

The study was conducted at multiple physician offices located in the USA. Based on US regulatory requirements to register a novel device, the primary objective was to demonstrate that a novel FeNO monitor, Fenom $\mathrm{PRO}^{\mathrm{mm}}$ (Spirosure, Pleasanton, CA, USA), can detect a significant change in FeNO, a marker of airway inflammation following short-term corticosteroid therapy prescribed for uncontrolled asthma. A secondary objective was to demonstrate that the change in FeNO after corticosteroid therapy was accompanied by improvement in $\mathrm{FEV}_{1}$, asthma symptoms, and the 6-item asthma control (ACQ6) scores. The study was approved by the BioMed institutional review board on December 8, 2016. The focus of this report is an evaluation of concordance for separate asthma domains in the study.

\section{Patient and public involvement}

There was no patient or public involvement in developing this protocol as all subjects were screened and recruited on the same day. No patients were involved in helping recruit this study and the results have not been communicated to the study participants.

\section{Study design and duration}

This was an open label, non-randomized, prospective, study evaluating FeNO, spirometry, asthma control and asthma symptoms in non-steroid-treated adult and pediatric subjects with uncontrolled asthma before and after 2-week corticosteroid treatment (see Fig. 1). The study consisted of two visits, V1 and V2, separated by a period of approximately 14 days. Subjects were started on high dose inhaled corticosteroids (ICS) with the addition of oral corticosteroids if clinically indicated. A safety follow-up telephone call occurred on Day $21 \pm 3$ such that the total duration of the study was a maximum of 24 days.

\section{Study population}

The study population comprised male and female subjects aged 5 years and older spontaneously presenting with uncontrolled asthma based on recent symptoms that required intervention. No specific etiology for the uncontrolled asthma is available. No asthma controllers were permitted including corticosteroids or leukotrienemodifying agents for 2 weeks and biologics for 12 weeks prior to enrolment. Subjects who were not already treated with a short-acting bronchodilator (SABA) were provided with such at Visit 1 . The subjects were required to have a FeNO level $>25$ parts per billion (ppb) (children $<18$ years of age), or $>30 \mathrm{ppb}$ (adults $\geq 18$ years old) at Visit 1, increasing the probability for an allergic asthma phenotype. This eligibility criterion for a raised $\mathrm{FeNO}$ is driven by regulatory requirements to show that a novel FeNO monitor can detect a reduction in FeNO after corticosteroid therapy. Subjects were excluded if they were cigarette smokers within the past 6 months, presented with $a \geq 10$ pack-year history of smoking, had other respiratory conditions, or had other clinically significant medical conditions.

\section{Primary endpoint}

The primary endpoint was the \% change from baseline from Visit 1 to Visit 2 in FeNO.

\section{Secondary endpoints}

Secondary endpoints included the change from baseline from Visit 1 to Visit 2 pre-bronchodilator $\mathrm{FEV}_{1}$, ACQ6 or the pediatric ACQ6 (pACQ6), and total day and

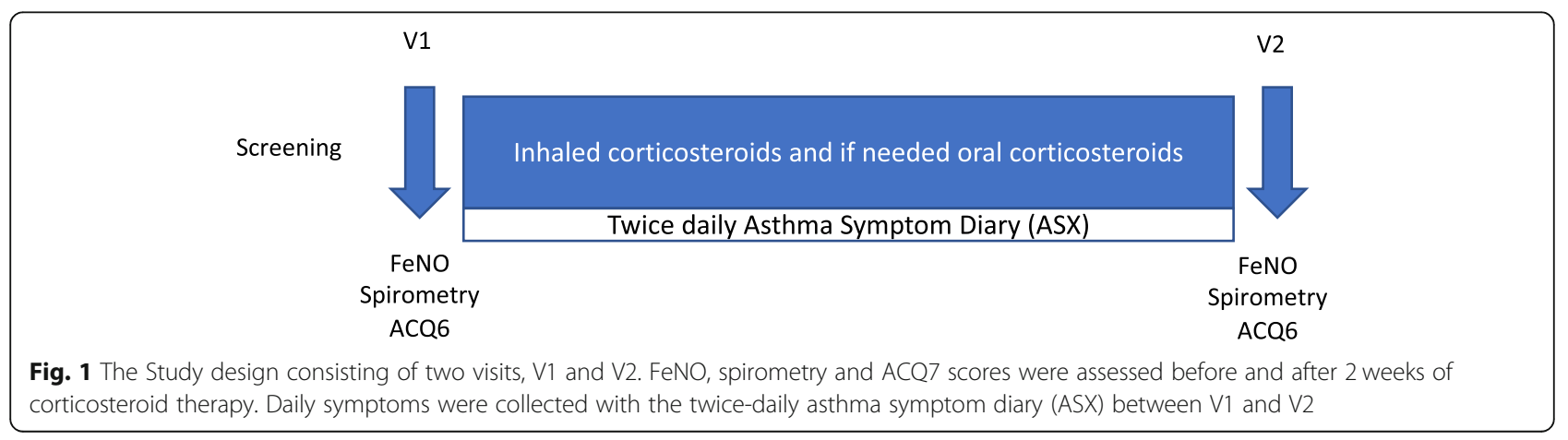


nighttime asthma symptoms (TASX) measured with a custom-built questionnaire for this study, the ASX, to be completed twice-daily by adult subjects and caregivers for pediatric subjects.

\section{Study procedures}

FeNO was measured using the recently-cleared Fenom $\mathrm{PRO}^{\mathrm{mm}}$ (see Fig. 2; Spirosure, Inc., Pleasanton, CA, USA) [2]. Fenom PRO simplifies the measurement process and provides rapid results in less than $30 \mathrm{~s}(\mathrm{~s})$. Fenom $\mathrm{PRO}^{\mathrm{mt}}$ monitors and encourages users to achieve an expiratory flow rate of $50 \mathrm{ml} / \mathrm{s}$ as recommended by the American Thoracic Society (ATS) guidelines from 2005. Subjects inhaled ambient air to total lung capacity, placed their lips on the mouthpiece, and exhaled while targeting a flow rate of $50 \mathrm{ml} / \mathrm{s}$ assisted by visual and auditory feedback indicating the actual exhalation flow rate versus the desired flow rate. The Fenom $\mathrm{PRO}^{\mathrm{m}}$ device indicates whether the required exhalation flow rate parameters were met. Repeated exhalations were allowed to achieve 2 valid exhalations.

Spirometry was measured using each clinic's spirometers that conformed to ATS guidelines.

Asthma control was captured using the ACQ6 and pediatric ACQ6 [3-5] before other study procedures.

Twice daily symptoms were captured using a custombuilt novel symptom diary, the ASX that surveyed asthma symptoms, namely wheezing, chest tightness cough and dyspnea as well as nighttime awakenings due to asthma. The ASX consists of five symptom questions regarding wheezing, coughing, tightness of the chest, breathlessness, and activity limitation during the day and

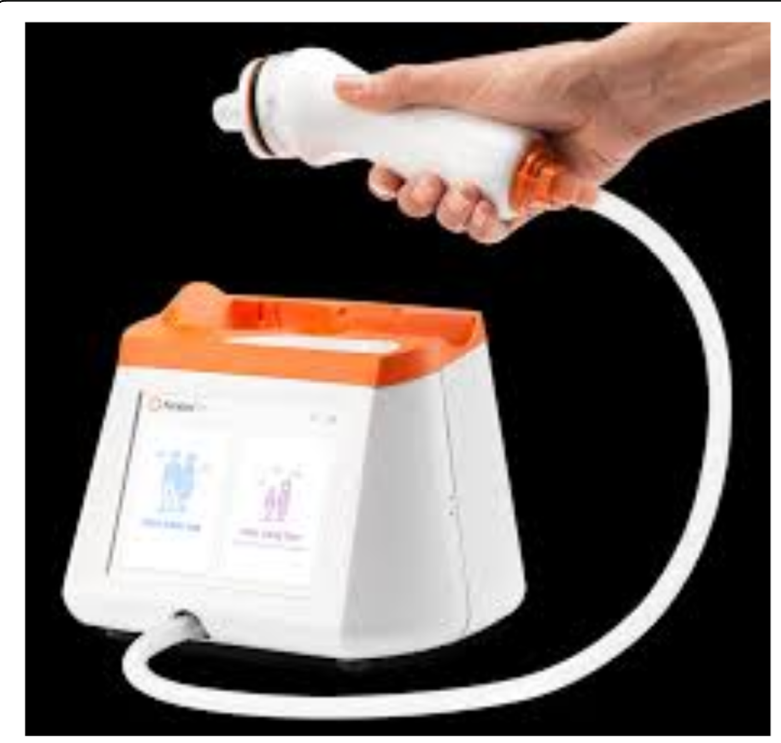

Fig. 2 The Fenom PRO device showing the handheld mouthpiece and mouth filter four symptom questions wheezing, coughing, tightness of the chest, breathlessness during the night each scored from 0 to 4 making a total potential score (TASX) of 36 for day and night together. There is no validated minimal important change (MID) for the TASX.

\section{Statistical methods}

The primary endpoint, the \% change from baseline (V1 to V2) in FeNO was analyzed via a two-sided paired ttest or Wilcoxon Signed Rank test, depending on the distribution of the data, at the 0.05 level of significance. The absolute changes for $\mathrm{FEV}_{1}$, ACQ6 and TASX were analyzed using the same method. The TASX scores were averaged over Day 1 and 2 after Visit 1 and the last 2 days before Visit 2 for the purpose of assessing change from Visit 1 to Visit 2. Investigation was made of the association of changes in all asthma domains by calculating correlation coefficients.

The concordance/discordance $(\mathrm{C} / \mathrm{D})$ was calculated for each pair of study outcomes (FeNO, ACQ6, FEV ${ }_{1}$, and TASX) using bidirectional changes (improving or worsening of asthma as indicated by each outcome) of any magnitude around their respective zero points and also the published minimal important differences (MID) for $\mathrm{FEV}_{1}$ (100 mls.) [6], ACQ6 (0.5) [5], and a significant change for FeNO of at least $10 \mathrm{ppb}$ based on the ATS recommendations from 2011 [7].

\section{Results}

The study was performed at 10 investigational sites in the USA. The study was approved by the BioMed IRB and all subjects or caregivers for minors underwent an informed consent procedure and signed consent forms and assent forms for minors.

\section{Subjects disposition}

Of 128 screened subjects, 85 enrolled into the study and 84 comprised the intent to treat population (ITT). Table 1 presents demographic variables for the ITT population $(n=84)$. All subjects were started on high dose ICS therapy while only three subjects were also started on OCS. Based on self-reported compliance in the daily diaries, 84 of 85 subjects complied with corticosteroid therapy started at V1. Only 1 subject reported not taking corticosteroid therapy for the entire duration of the study.

\section{Asthma characteristics at baseline}

Table 2 presents baseline asthma characteristics for the ITT population. In general, this was a mild population based on a mean \% predicted $\mathrm{FEV}_{1}$ of $82.7 \%$ although subjects had a wide $\mathrm{FEV}_{1}$ range (26.8-139.5\%), and on average had markedly uncontrolled asthma, with a mean 
Table 1 Demographics and relevant medical history for the ITT population at baseline, $\mathrm{V} 1$

\begin{tabular}{|c|c|}
\hline \multicolumn{2}{|l|}{ Age (years) } \\
\hline$n$ & 84 \\
\hline Mean & 28.9 \\
\hline SD & 19.48 \\
\hline Median & 19.5 \\
\hline Min, Max & 8,79 \\
\hline \multicolumn{2}{|l|}{ Age, n (\%) } \\
\hline $5-11$ years & $12(14.3)$ \\
\hline $12-17$ years & $26(31.0)$ \\
\hline$>=18$ years & $46(54.8)$ \\
\hline \multicolumn{2}{|l|}{ Sex, n (\%) } \\
\hline Male & $48(57.1)$ \\
\hline Female & $36(42.9)$ \\
\hline \multicolumn{2}{|l|}{ Race, n (\%) } \\
\hline Caucasian & $60(71.4)$ \\
\hline Black or African American & $13(15.5)$ \\
\hline Asian & $4(4.8)$ \\
\hline American Indian or Alaskan Native & 0 \\
\hline Native Hawaiian/Pacific Islander & 0 \\
\hline Two or more races & $3(3.6)$ \\
\hline Other & $4(4.8)$ \\
\hline \multicolumn{2}{|l|}{ Ethnicity, n (\%) } \\
\hline Hispanic or Latino & $19(22.6)$ \\
\hline Not Hispanic or Latino & $64(76.2)$ \\
\hline Unknown/Not Provided & $1(1.2)$ \\
\hline${ }^{\mathrm{a} F o o d}$ allergy & $30.1 \%$ \\
\hline${ }^{a}$ Allergic rhinitis & $18.1 \%$ \\
\hline${ }^{a}$ Atopic dermatitis & $3.5 \%$ \\
\hline Asthma age of onset mean (SD) & $8.4(11.8)$ \\
\hline Asthma duration mean (SD) & $18.4(15.9)$ \\
\hline
\end{tabular}

abased on commonest term captured in the medical history at screening

(95\%CL) ACQ6/pACQ6 of 2.06 (1.83-2.29) where uncontrolled asthma is defined as a score $>1.5$.

\section{Primary endpoint}

For the primary endpoint in the ITT population, the \% change in FeNO from Visit 1 to 2, was - 51.4\% (absolute change $-41.7 \mathrm{ppb}), p<0.0001$ as shown in Table 3. Figure 3 presents a box plot of FeNO values (in absolute $\mathrm{ppb})$ at Visit 1 and Visit 2 with overlaid line plotting for each individual subject indicating the change of FeNO values from V1 to V2. As shown, FeNO values decreased for the majority of subjects following corticosteroid treatment. A subanalysis of the primary endpoint in those subjects from the ITT population reporting at least one allergy diagnosis in the medical history
Table 2 Asthma characteristics at baseline, for the ITT population at $\mathrm{V} 1$

\begin{tabular}{|c|c|}
\hline \multicolumn{2}{|l|}{$\mathrm{FEV}_{1}(\mathrm{~L})$} \\
\hline $\mathrm{n}$ & 84 \\
\hline Mean & 2.676 \\
\hline SD & 0.9115 \\
\hline Median & 2.675 \\
\hline Min, Max & $0.79,5.11$ \\
\hline \multicolumn{2}{|l|}{ FVC (L) } \\
\hline $\mathrm{n}$ & 84 \\
\hline Mean & 3.625 \\
\hline SD & 1.2339 \\
\hline Median & 3.710 \\
\hline Min, Max & $1.40,6.82$ \\
\hline \multicolumn{2}{|l|}{$\mathrm{FEV}_{1} / \mathrm{FVC}$} \\
\hline$n$ & 84 \\
\hline Mean & 74.355 \\
\hline SD & 10.4398 \\
\hline Median & 74.164 \\
\hline Min, Max & $52.72,120.00$ \\
\hline \multicolumn{2}{|c|}{$\%$ Predicted FEV 1} \\
\hline$n$ & 84 \\
\hline Mean & 82.72 \\
\hline SD & 17.250 \\
\hline Median & 83.75 \\
\hline Min, Max & $26.8,139.5$ \\
\hline \multicolumn{2}{|c|}{ ACQ6 and pACQ6 } \\
\hline $\mathrm{n}$ & 84 \\
\hline Mean & 2.056 \\
\hline SD & 1.033 \\
\hline Median & 1.833 \\
\hline Min, Max & $0.17,5.33$ \\
\hline
\end{tabular}

captured at screening, showed that FeNO fell by $-50,6 \%$ $(p<0.00001)$. This indicates that the population for the most part had allergic asthma and that the FeNO change after corticosteroids was similar to the ITT population as a whole.

\section{Secondary outcomes}

There were highly significant improvements in $\mathrm{FEV}_{1}$, ACQ6/pACQ6 and TASX (Table 3) from Visit 1 to Visit 2. The change in TASX for the ITT population is shown in Fig. 4. Of note, the values at Days 15-17 vary considerably due to the fact that few subjects $(N=14,3$, and 2 , respectively) continued treatment out to these time points, which were within the allowable window of 3 days beyond Visit 2. 
Table 3 The change in asthma outcomes from V1 to V2 for the ITT population

\begin{tabular}{|c|c|c|c|}
\hline FeNO (ppb) & Visit 1 & Visit 2 & Change $\mathrm{V} 1$ to $\mathrm{V} 2$ \\
\hline$n$ & 84 & 84 & 84 \\
\hline Mean & 81.13 & 39.42 & -41.71 \\
\hline s.d. & 48.748 & 24.191 & 45.058 \\
\hline$\%$ change from baseline & - & - & -51.4 \\
\hline$p$-value & - & - & $<.0001$ \\
\hline \multicolumn{4}{|l|}{ ACQ6/pACQ6 } \\
\hline$n$ & 84 & 84 & 84 \\
\hline mean & 2.056 & 1.044 & -1.000 \\
\hline s.d. & 1.033 & 0.6205 & 1.1264 \\
\hline$p$-value & & & $<.0001$ \\
\hline \multicolumn{4}{|l|}{$\mathrm{FEV}_{1}(\mathrm{~L})$} \\
\hline $\mathrm{n}$ & 84 & 84 & 84 \\
\hline mean & 2.676 & 2.883 & 0.207 \\
\hline s.d. & 0.9115 & 0.8926 & 0.3518 \\
\hline $\mathrm{p}$-value & & & $<.0001$ \\
\hline \multicolumn{4}{|l|}{ TASX } \\
\hline$n$ & 81 & 81 & 81 \\
\hline Mean & 4.43 & 3.03 & -1.40 \\
\hline s.d. & 3.80 & 3.06 & 2.22 \\
\hline $\mathrm{p}$-value & - & & $<0.0001$ \\
\hline
\end{tabular}

\section{Correlation between changes in asthma domains}

Table 4 reports a matrix for simple Pearson correlations for the absolute changes in FeNO and other secondary measures as well as the \% changes in FeNO and other measures. The following comparisons showed modest correlation: absolute and \% changes in FeNO vs changes in ACQ6/pACQ6 ( $\mathrm{r}$ values in the range $0.24-0.25 ; p$ values 0.0280 and 0.0203 , respectively), absolute changes in ACQ6 vs $\mathrm{FEV}_{1}(\mathrm{r}=-0.21, p=0.0580)$, and absolute and \% changes in ACQ6 vs TASX ( $\mathrm{r}$ values in the 0.29 0.35 , p values 0.0015 and 0.0105 , respectively).

\section{Concordance/discordance for the combined ITT population}

Concordance/discordance were assessed between each pair of asthma domains for any change around 0 (Table 5) and for changes around the MID (Table 6) for the combined adult and pediatric ITT population. Table 7 (Panel A) presents the data in descending order for the concordance between pairs of domains for changes around 0. It can be seen that FeNO and ACQ6 have the highest concordance whereas $\mathrm{FEV}_{1}$ versus ACQ6 and TASX occupy the 2 lowest concordance values.

\section{Changes around MID}

In Table 7 Panel $\mathrm{B}$, it can be seen that concordance for changes around the MID for all comparisons increases and the order is the same as for changes around 0 . The concordance between pairs of domains was still highest for FeNO and ACQ6 with changes between ACQ6 and TASX, both symptom assessment instruments second highest. $\mathrm{FEV}_{1}$ was the most discordant when assessed against ACQ6 and TASX but demonstrated the third highest concordance with FeNO for both changes around 0 and the MID. Of note, only $17 / 82$ subjects demonstrated concordant

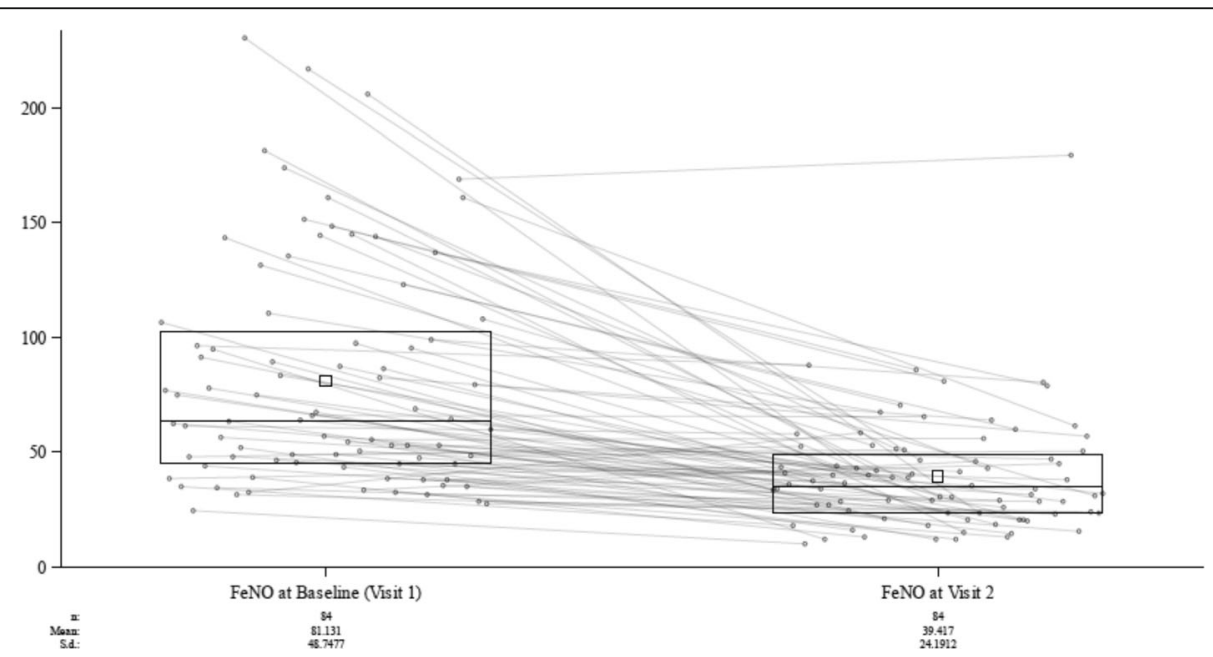

Fig. 3 A box plot of FeNO values (ppb) at Visit 1 and Visit 2 for the ITT population with overlaid line plotting of all subjects in the ITT population. The lower and upper bounds of the boxes represent the 25th and 75th percentiles of the distributions (the interquartile range) and the internal box symbols and horizontal lines within each box represent the mean and median values, respectively. The figure indicates the diminution of FeNO values across the population as a result of corticosteroid therapy 


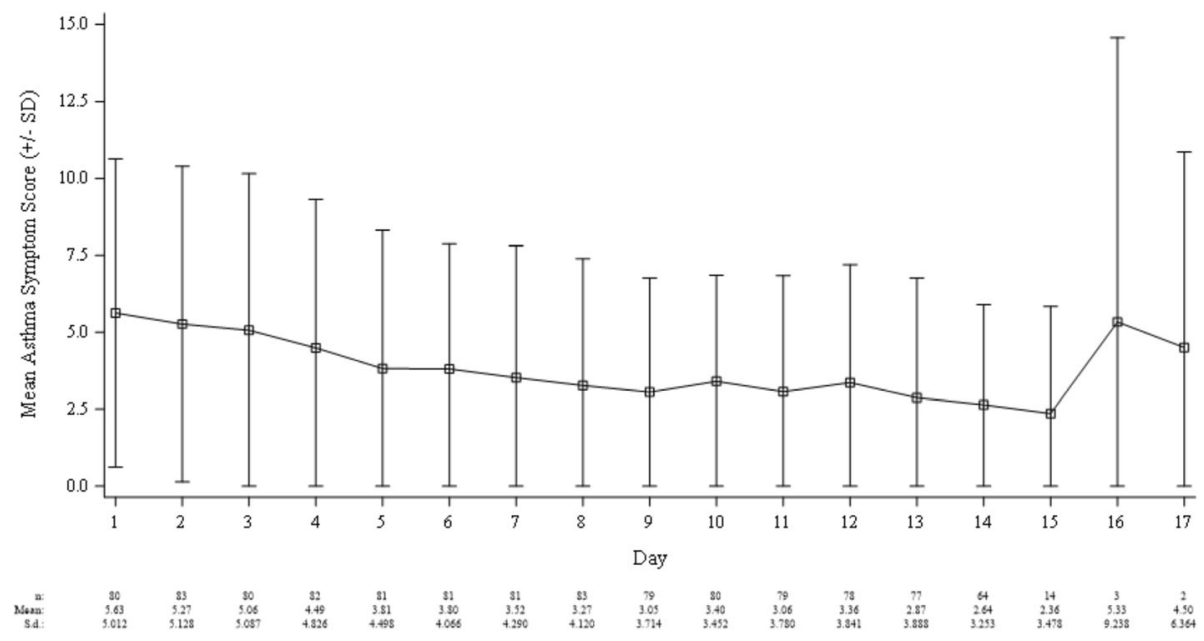

Fig. 4 The total asthma symptom scores by study day. The plot includes 1 standard deviation error bars (limited on the lower bound to a value of 0.0 so as to avoid negative values) and notes the sample size $(N$, ) mean, and SD of each time point. Of importance, Days 15, 16, and 17 (the allowable window of 3 days beyond Visit 2) includes a small number of observations at $N=14,3$, and 2, respectively (denoted by separate boxed area in the plot). In general, asthma symptom scores decrease from Days 1-15. Due to low N, the estimates for Days 16 and 17 do not provide confidence in any trend

MID changes for improvement for the three variables $\mathrm{FEV}_{1}$, ACQ6 and FeNO (data not shown).

\section{Concordance/discordance for the adults and pediatric ITT populations separately}

When considering the adult and pediatric populations separately, the findings were similar to those presented for the combined ITT populations (data shown in Table 8, panels A and B and supplemental Tables E1E4). Again, when moving from changes around 0 to MID changes, there was a universal increase in concordance (Table 8). For changes around 0, for adults alone, $\mathrm{FEV}_{1}$ concordance with TASX and ACQ6 remained the lowest, and FeNO vs ACQ6 was still the highest. For the pediatric population, $\mathrm{FEV}_{1}$ vs TASX was still the lowest concordance, but ACQ6 and TASX had the highest concordance. For changes around the MID, TASX vs ACQ6 was the highest and $\mathrm{FEV}_{1}$ vs TASX the lowest for adults and children.

\section{Discussion}

We report for the first time the degree of concordance between dynamic changes in asthma domain measures for airway inflammation (FeNO), lung function $\left(\mathrm{FEV}_{1}\right)$, asthma control (ACQ6/pACQ6) and daily symptoms (TASX) in steroid naïve adults and children after approximately 2 weeks of corticosteroid therapy. Of note, change in FeNO showed the highest concordance with change in ACQ6 for the combined ITT, adult, and pediatric populations for changes around 0 and for changes around the MID. In general, change in $\mathrm{FEV}_{1}$ demonstrated lowest concordances versus change in the

Table 4 Correlation between changes from V1 to V2 in asthma domains for the combined adult and pediatric ITT population

\begin{tabular}{|c|c|c|c|c|}
\hline & Change FEV 1 L & Change FeNO ppb & Change ACQ6 & Change TASX \\
\hline \multicolumn{5}{|l|}{ Change $\mathrm{FEV}_{1} \mathrm{~L}$} \\
\hline Change FeNO ppb & $-0.14 P=0.2161$ & & & \\
\hline Change ACQ6 & $-0.21 P=0.0580$ & $0.24 P=\mathbf{0 . 0 2 8 0}$ & & \\
\hline \multirow[t]{2}{*}{ Change TASX } & $-0.06 P=0.5843$ & $0.13 P=0.2571$ & $0.35 P=0.0015$ & \\
\hline & $\%$ Change FEV 1 & \% Change FeNO & \% Change ACQ6 & $\%$ Change TASX \\
\hline \multicolumn{5}{|l|}{$\%$ Change $\mathrm{FEV}_{1}$} \\
\hline$\%$ Change FeNO & $-0.09 P=0.4210$ & & & \\
\hline \% Change ACQ6 & $-0.14 P=0.2057$ & $0.25 \boldsymbol{P}=\mathbf{0 . 0 2 0 3}$ & & \\
\hline$\%$ Change TASX & $0.03 P=0.7740$ & $0.12 P=0.3209$ & $0.29 P=0.0105$ & \\
\hline
\end{tabular}


Table 5 Concordance (in bold text) and discordance for changes between pairs of asthma domains from V1 to V2 for any change around 0 for the combined adult and pediatric PP population

\begin{tabular}{|c|c|c|c|c|c|c|c|}
\hline \multirow{2}{*}{$\begin{array}{l}\text { Absolute } \\
\text { values }\end{array}$} & & \multicolumn{2}{|l|}{$\mathrm{FEV}_{1}$ change } & \multicolumn{2}{|c|}{ ACQ6 change } & \multicolumn{2}{|c|}{ TASX change } \\
\hline & & Improve & Worsen & Improve & Worsen & Improve & Worsen \\
\hline \multirow[t]{2}{*}{ FeNO change } & Improve & $54(65.9 \%)$ & $19(23.2 \%)$ & 62 (75.6\%) & $11(13.4 \%)$ & $54(66.7 \%)$ & 18 (22.2\% \\
\hline & Worsen & $4(4.9 \%)$ & $5(6.1 \%)$ & $6(7.3 \%)$ & $3(3.7 \%)$ & $6(7.4 \%)$ & $3(3.7 \%)$ \\
\hline \multirow[t]{2}{*}{ FEV1 change } & Improve & & & 48 (58.5\%) & $10(12.2 \%)$ & 42 (51.9\%) & 16 (19.8\% \\
\hline & Worsen & & & $20(24.4 \%)$ & 4 (4.9\%) & $18(22.2 \%)$ & $5(6.2 \%)$ \\
\hline \multirow[t]{2}{*}{ ACQ6 change } & Improve & & & & & $53(65.4 \%)$ & $14(17.3 \%$ \\
\hline & Worsen & & & & & 7 (8.6\%) & $7(8.6 \%)$ \\
\hline
\end{tabular}

other domains with the exception of FeNO. Of note, only 17 of 82 subjects demonstrated concordant ACQ6, $\mathrm{FEV}_{1}$, and FeNO changes reflecting improvement.

Based on the findings, the message is clear that the asthma domains of airway inflammation, symptoms, asthma control and lung function demonstrate significant discordance for changes over time. Mechanistically, there is of course a relationship between these domains. Airway inflammation, regarded as a primary driver can worsen airflow limitation, and bronchial hyperresponsiveness, and produce symptoms e.g. wheezing, chest tightness, and dyspnea. Airway inflammation also increases during the night, and this can account for nocturnal asthma. Asthma control measures such as ACQ6 reflect a constellation of symptoms, and recue medication use. A comprehensive assessment of asthma at any timepoint therefore requires the measurement of asthma symptoms and control, lung function, and airway inflammation.

The high concordance of FeNO with ACQ6 suggests that FeNO may be a primary driver of other asthma domains, i.e. airway inflammation drives changes in other domains. The ACQ6 includes 5 symptom questions (items 1-5), as well as rescue medication use (item 6) and thus includes two asthma domains, taking rescue use as a separate domain. ACQ6 and TASX also show high concordance which is predictable as both assess asthma symptoms. The relatively low concordance of
$\mathrm{FEV}_{1}$ with ACQ6 and TASX may be related to a component of fixed airflow obstruction or other reasons. However, FeNO and $\mathrm{FEV}_{1}$ demonstrate higher concordance which might be explained by airway wall inflammation causing worsening in airflow obstruction due to edema, mucus gland hypertrophy and smooth muscle hyperresponsiveness.

The lack of concordance or tight correlation between these domains can be explained in several ways. First, there may be heterogeneous degrees of abnormality for each domain present in individual patients at a single time point and there is a correlation between the change in a domain and the degree of abnormality in that domain (room for change). For example, one patient may have significant airway inflammation but low symptomatology, either because they have yet to experience deteriorating lung function, or they may be poor perceivers and are not sensitive to their lung function decline. Conversely, another patient with marked symptoms may not have elevated airway inflammation if their symptoms are due to fixed reduction in lung function due to airway remodeling.

Second, when patients receive corticosteroids or other interventions as in the study reported here, there may be disparate time courses for change of the individual components. In a 2-week study as was done here, the change in FeNO is probably complete, but symptoms, asthma control and lung function may still be improving and

Table 6 Concordance (in bold text) and discordance for changes between pairs of asthma domains from V1 to V2 for changes equal or greater than the MID (a subset of the PP population). For FeNO, a change of 10 ppb was used (ATS, 2011) whereas for TASX, changes around 0 were used as no MID is available

\begin{tabular}{|c|c|c|c|c|c|c|c|}
\hline \multirow{2}{*}{$\begin{array}{l}\text { Absolute } \\
\text { values }\end{array}$} & & \multicolumn{2}{|l|}{$\mathrm{FEV}_{1}$ change } & \multicolumn{2}{|c|}{ ACQ6 change } & \multicolumn{2}{|c|}{ TASX change } \\
\hline & & Improve & Worsen & Improve & Worsen & Improve & Worsen \\
\hline \multirow[t]{2}{*}{ FeNO change } & Improve & 25 (80.7\%) & $6(19.4 \%)$ & 43 (93.5\%) & $2(4.4 \%)$ & 45 (75.0\%) & $13(21.7 \%)$ \\
\hline & Worsen & $0(0.0 \%)$ & $0(0.0 \%)$ & $1(2.2 \%)$ & $0(0.0 \%)$ & $1(1.7 \%)$ & $1(1.7 \%)$ \\
\hline \multirow[t]{2}{*}{$\mathrm{FEV}_{1}$ change } & Improve & & & $22(71.0 \%)$ & 2 (6.5\%) & $26(56.5 \%)$ & $10(21.7 \%)$ \\
\hline & Worsen & & & $6(19.4 \%)$ & $1(3.2 \%)$ & $8(17.4 \%)$ & $2(4.4 \%)$ \\
\hline \multirow[t]{2}{*}{ ACQ6 change } & Improve & & & & & $43(75.4 \%)$ & 9 (15.8\%) \\
\hline & Worsen & & & & & $1(1.8 \%)$ & $4(7.0 \%)$ \\
\hline
\end{tabular}


Table 7 Concordance/discordance for pairs of asthma domains considering changes from V1 to V2 considering any change $>0$ and changes at < or > than the MID level for the combined adult and pediatric ITT population. The Table is organized in descending order for the data for changes around 0

\begin{tabular}{lll}
\hline Asthma domain & $\begin{array}{l}\text { Panel A (ITT population) } \\
\text { Changes }>\text { or }<0 \text { Concordance/discordance }(\%)\end{array}$ & Panel B (PP population) \\
& $\mathbf{7 9 . 3 / 2 0 . 7}$ & Changes $>$ of < MID Concordance/discordance $(\%)$ \\
\hline FeNO and ACQ6 & $74.0 / 25.9$ & $\mathbf{9 3 . 5 / 6 . 6}$ \\
ACQ6 and TASX & $71.9 / 28.1$ & $82.4 / 17.6^{*}$ \\
FeNO and FEV1 & $70.4 / 29.6$ & $80.7 / 19.4$ \\
FeNO and TASX & $63.4 / 36.6$ & $76.7 / 23.3^{*}$ \\
FEV1 and ACQ6 & $58.1 / 41.9$ & $74.2 / 25.9$ \\
FEV1 and TASX & & $60.9 / 39.1^{*}$ \\
\hline
\end{tabular}

may not be at a steady state. The $\mathrm{FEV}_{1}$ response to ICS in particular may still be improving many weeks later.

Third, the development of airway remodeling in certain patients over many years may lead to persistent airflow obstruction (low $\mathrm{FEV}_{1}$ ) that does not respond to a significant degree, whereas FeNO and ACQ6 respond. Conversely, lung function can be near normal in some subjects, especially children, and thus may not have room for improvement.

Finally, one must also consider the intrinsic limitations of all domain measures. FeNO measures one proinflammatory mediator and cannot reflect the entire complexity of airway inflammation present in an individual patient. Indeed, some of the subjects may have had neutrophilic inflammation with or without eosinophilic inflammation, which may not have responded to corticosteroids. $\mathrm{FEV}_{1}$ is less sensitive to small airway airflow limitation and cannot reflect airflow limitation throughout the airway tree. ACQ6/pACQ6 while well validated may not capture the entire asthma experience.

The asthma symptom questionnaire (ASX) was used here for the first time and is yet to be validated as a patient reported outcome but seems to show promise demonstrating high concordance with ACQ6 in the combined and separate adult and pediatric populations but lower concordance with $\mathrm{FEV}_{1}$. This is perhaps to be expected as both ACQ6 and ASX are symptom domains.

The lack of perfect concordance between asthma domains has been observed in the literature. Kaminski, et al. studied the impact of attendance at a 1-week summer camp on asthma domains in children with asthma [8]. At the end of camp, FeNO showed a decrease of $45 \%(p<0.0001)$ whereas ACQ7 only fell by $14 \%$ ( $p=$ 0.72) and mean $\mathrm{FEV}_{1} \%$ predicted remained unchanged.

Khalili et al. reported no significant association was found between FeNO level and several measures of

Table 8 Concordance/discordance for pairs of asthma domains considering changes from V1 to V2 considering any change around 0 (ITT population) and changes at the MID level (PP population) for the adult (Panel A) and pediatric (Panel B) populations. The Table is organized in descending order for the data for changes around 0

\begin{tabular}{lll}
\hline Asthma domain & Changes $>$ or $<0$ Concordance/discordance (\%) & Changes $>$ of $<$ MID Concordance/discordance $(\%)$ \\
\hline Panel A (adult ITT population) & & $\mathbf{9 6 . 2 / 3 . 9}$ \\
FeNO and ACQ6 & $\mathbf{8 2 . 2 / 1 7 . 7}$ & $75.0 / 25.0$ \\
FeNO and TASX & $72.7 / 27.3$ & $74.2 / 25.8$ \\
ACQ6 and TASX & $68.2 / 31.8$ & $76.2 / 23.8$ \\
FeNO and FEV 1 & $66.6 / 33.4$ & $61.3 / 38.7$ \\
FEV $_{1}$ and TASX & $59.1 / 40.9$ & $81.0 / 19.1$ \\
FEV $_{1}$ and ACQ6 & $57.8 / 42.3$ & \\
Panel B (pediatric population) & & $\mathbf{9 2 . 3 / 7 . 7}$ \\
ACQ6 and TASX & $\mathbf{8 1 . 1 / 1 8 . 9}$ & $90.0 / 10.0$ \\
FeNO and FEV 1 & $78.4 / 21.6$ & $90.0 / 10.0$ \\
FeNO and ACQ6 & $75.7 / 24.3$ & $60.0 / 40.0$ \\
FEV ${ }_{1}$ and ACQ6 & $70.3 / 29.7$ & $78.6 / 21.5$ \\
FeNO and TASX & $67.6 / 32.4$ & $60.0 / 40.0$ \\
FEV ${ }_{1}$ and TASX & $56.8 / 43.2$ & \\
\hline
\end{tabular}


asthma control including the ACQ7, and the Asthma Control Test (ACT) [9]. Quadvlieg, et al. reported a similar lack of correlation between FeNO and ACQ7 in 134 patients with asthma [10]. Patients were divided into the three groups according to their level of asthma control determined by ACQ7 [well-controlled asthma (ACQ7 score $<0.75)$, borderline $(0.75<\mathrm{ACQ7}$ score $<$ 1.5) and uncontrolled asthma (ACQ7 score $\geq 1.5$ )]. There were no significant differences in the FeNO levels between the groups.

Thomas et al. evaluated FeNO, lung function, ACQ7, and the Royal College of Physicians 3 questions (RCP scores) in 35 adults and children with asthma at 2-week intervals over 12 weeks [11]. Weak or absent correlations existed with lung function and there were no correlations with FeNO levels. In a report by Obase, et al. [12], during step down or continuation of inhaled corticosteroid therapy, FeNO levels increased or decreased, respectively, without change in lung function or symptoms assessed by ACQ7. The authors conclude that caution is needed when stepping down corticosteroid therapy solely based on symptoms or lung function. The Airways Disease Endotyping for Personalized Therapeutics (ADEPT) study evaluated FeNO and multiple asthma characteristics in 157 adult asthmatics of varying severity [13]. FeNO did not demonstrate any significant or meaningful associations with lung function or ACQ7. In a metanalysis of the efficacy of anti-interleukin-13 therapies in asthma, Luo, et al. reported that treatment significantly improved peak expiratory flow (PEF), decreased FeNO and asthmatic exacerbation rate, but without decrease in blood or sputum eosinophil levels, improvement in $\mathrm{FEV}_{1}$, or reduction in ACQ7 scores [14]. In a study of the effects of exercise and/or diet on asthma control in 125 obese asthmatic patients, Toennesen reported that in the group receiving both interventions, ACQ7 fell significantly compared to either intervention alone, but there were no significant changes in $\mathrm{FEV}_{1}$ or ACQ7 in any of the groups [15].

In addition to the concordance reported here for changes in asthma domains, others have noted the low concordance between domains at a single time point $[16,17]$. If asthma domains display discordance at a single timepoint, it is logical that changes in these parameters over time would be similar.

Weaknesses of our study include the absence of objective measures of compliance with corticosteroid therapy, although self-reported compliance was very high. Additionally, while there are established MIDs for ACQ6 and $\mathrm{FEV}_{1}$, for FeNO there is no established MID and therefore we used the ATS definition of a meaningful change from 2011 of $10 \mathrm{ppb}$ [7] though this might be suboptimal. In addition, the MIDs we used may not themselves be universally applicable e.g. for children.

\section{Conclusion}

In conclusion, while there is substantial concordance between changes in the asthma domains following shortterm corticosteroid therapy, there is moderate discordance especially between $\mathrm{FEV}_{1}$ and other domains. The findings highlight the complex relationships between asthma domains and emphasize the wisdom of assessing multiple parameters in order to fully understand an individual patient's asthma.

\section{Supplementary information}

Supplementary information accompanies this paper at https://doi.org/10. 1186/s12890-020-1166-2.

Additional file 1: Table E1. Concordance (bolded) and discordance for changes between pairs of asthma domains from V1 to V2 for any change around zero (adults only) for the PP population. Table E2. Concordance (bolded) and discordance for changes between pairs of asthma domains from V1 to V2 for changes equal or greater than the MID (adults only) For FeNO, a change of $10 \mathrm{ppb}$ was used (ATS, 2011) whereas for TASX, changes around 0 were used as no MID is available for the PP population. Table E3. Concordance (bolded) and discordance for changes between pairs of asthma domains from V1 to V2 for any change around zero (pediatric subjects only) for the PP population Table E4. Concordance (bolded) and discordance for changes between pairs of asthma domains from V1 to V2 for changes equal or greater than the MID (pediatric subjects only) for the PP population. For FeNO, a change of 10 ppb was used (ATS, 2011) whereas for TASX, changes around 0 were used as no MID is available.

\section{Abbreviations}

FeNO: Fractional concentration of exhaled nitric oxide; FEV $_{1}$ : Forced expired volume in one second; ACQ6 or ACQ7: Asthma control questionnaire (6 item or 7-item); ASX: Asthma symptom questionnaire; TASX: Total score from the ASX; AM: Morning; PM: Evening; C: Concordance; D: Discordance; C.D: Concordance/discordance; MID: Minimal important difference (clinical); ICS: Inhaled corticosteroids; OCS: Oral corticosteroids; SABA: Short-acting bronchodilator; ATS: American Thoracic Society; V: Visit; ITT: Intent to Treat; RCP: Royal College of Physicians; ADEPT : Airways Disease Endotyping for Personalized Therapeutics; PEF: Peak Expiratory Flow; IgE: Immunoglobulin E

\section{Acknowledgements}

We wish to acknowledge the following individuals: Clinical investigators: David Bernstein MD (Cincinatti, OH, USA), Lawrence Sher MD (Rolling Hills, CA), Neil Parikh MD (Roeville, CA, USA), Luke Webb MD (Colorado Springs, CO, USA), Sarah Kehl MD (Eugene, OR, USA), Nancy Ostrom MD (San Diego, CA, USA), Joshua Jacobs MD (Walnut Creek, CA, USA), Neal Jain MD (Gilbert, AZ, USA), Paul Ratner MD (San Antonio, TX, USA), Frank Hampel MD(New Braunfels, TX, USA). Vision Clinical Research: San Diego California: Michael Lichtman, Guy Gammon MD, and White Consulting (Las Vegas, NV, USA): Vicki White

\section{Authors' contributions}

PES designed the study and authored the manuscript. MS provided CRO services for the study, provided the statistical plan, performed the analyses for the study and reviewed the manuscript. SS, VB, BA and RL participated in designing and running the study, and provided the exhaled nitric oxide technology for the study and all reviewed the manuscript. The authors read and approved the final manuscript.

\section{Funding}

The study was funded by Spirosure Inc.

\section{Availability of data and materials}

The datasets generated and/or analyzed during the current study are not publicly available as these are propriety but are available from Spirosure Inc. on reasonable request. 


\section{Ethics approval and consent to participate}

The study was approved by the BioMedical Research Institute of America, P.O. Box 600870, San Diego, CA 92160, on 12/8/16 (there is no approval number). All subjects or caregivers, where the participant was under 18 years of age, gave their verbal agreement after a detailed explanation of the objectives and necessary procedures for the study, and all subjects or their caregivers where the subject was under 18 years of age signed a written informed consent for the study, and minors signed an assent from, after being given adequate time to read these.

\section{Consent for publication}

There is no individual patient data so consent for publication was not requested.

\section{Competing interests}

PES is a paid consultant for Spirosure Inc. and holds stock options in the company.

MS is a paid contractor for Spirosure and provided the contract research organization (CRO) services to run the study.

All the remaining authors are full-time employees of Spirosure and hold stock options in the company.

\section{Author details}

'Philadelphia, USA. Vision Clinical Research, 1501 San Elijo Road, Suite 104, \#213, San Marcos, CA 92078, USA. ${ }^{3}$ Spirosure Inc, 7020 Koll Center Pkwy

\#110, Pleasanton, CA 94566, USA.

Received: 28 August 2019 Accepted: 27 April 2020

Published online: 14 May 2020

\section{References}

1. Silkoff P. History, technical and regulatory aspects of exhaled nitric oxide. J Breath Res. 2008;2(3):037001.

2. Silkoff PE, Awabdy B, Sarno M, Ssenyange S, Balsubramanyam V, Leard R. Clinical precision, accuracy, number and durations of exhalations for a novel electrochemical monitor for exhaled nitric oxide. J Breath Res. 2019;14(1): 016011.

3. Juniper EF, Gruffydd-Jones K, Ward S, Svensson K. Asthma control questionnaire in children: validation, measurement properties, interpretation. Eur Respir J. 2010;36(6):1410-6.

4. Juniper EF, O'Byrne PM, Guyatt GH, Ferrie PJ, King DR. Development and validation of a questionnaire to measure asthma control. Eur Respir J. 1999; 14(4):902-7.

5. Juniper EF, Svensson K, Mork AC, Stahl E. Measurement properties and interpretation of three shortened versions of the asthma control questionnaire. Respir Med. 2005:99(5):553-8.

6. Jones PW, Beeh KM, Chapman KR, Decramer M, Mahler DA, Wedzicha JA. Minimal clinically important differences in pharmacological trials. Am J Respir Crit Care Med. 2014;189(3):250-5.

7. Dweik RA, Boggs PB, Erzurum SC, Irvin CG, Leigh MW, Lundberg JO, Olin AC, Plummer AL, Taylor DR, American Thoracic Society Committee on Interpretation of Exhaled Nitric Oxide Levels for Clinical. An official ATS clinical practice guideline: interpretation of exhaled nitric oxide levels (FENO) for clinical applications. Am J Respir Crit Care Med. 2011;184(5):60215.

8. Kaminsky DA, Rice AA, Bissonette M, Larose T, Phillips L, Cohen L, Lahiri T, Frankowski B. Exhaled nitric oxide decreases in association with attendance at an asthma summer cAMP. J Asthma. 2008;45(5):415-9.

9. Khalili B, Boggs PB, Shi R, Bahna SL. Discrepancy between clinical asthma control assessment tools and fractional exhaled nitric oxide. Ann Allergy Asthma Immunol. 2008;101(2):124-9.

10. Quaedvlieg V, Sele J, Henket M, Louis R. Association between asthma control and bronchial hyperresponsiveness and airways inflammation: a cross-sectional study in daily practice. Clin Exp Allergy. 2009;39(12):1822-9.

11. Thomas M, Gruffydd-Jones K, Stonham C, Ward S, Macfarlane TV. Assessing asthma control in routine clinical practice: use of the Royal College of Physicians '3 questions'. Prim Care Respir J. 2009;18(2):83-8.

12. Obase $Y$, Ikeda M, Kurose K, Abe M, Shimizu H, Ohue Y, Mouri K, Katoh S, Kobashi Y, Oka M. Step-down of budesonide/formoterol in early stages of asthma treatment leads to insufficient anti-inflammatory effect. J Asthma. 2013;50(7):718-21.
13. Silkoff PE, Strambu I, Laviolette M, Singh D, FitzGerald JM, Lam S, Kelsen S, Eich A, Ludwig-Sengpiel A, Hupp GC, et al. Asthma characteristics and biomarkers from the airways disease Endotyping for personalized therapeutics (ADEPT) longitudinal profiling study. Respir Res. 2015:16:142.

14. Luo J, Liu D, Liu CT. The efficacy and safety of Antiinterleukin 13, a monoclonal antibody, in adult patients with asthma: a systematic review and meta-analysis. Medicine (Baltimore). 2016;95(6):e2556.

15. Toennesen LL, Meteran H, Hostrup M, Wium Geiker NR, Jensen CB, Porsbjerg C, Astrup A, Bangsbo J, Parker D, Backer V. Effects of exercise and diet in nonobese asthma patients-a randomized controlled trial. J Allergy Clin Immunol Pract. 2018;6(3):803-11. https://doi.org/10.1016/j.jaip.2017.09. 028.

16. Thomas B, Chay OM, Allen JC Jr, Chiang AS, Pugalenthi A, Goh A, Wong P, Teo AH, Tan SG, Teoh OH. Concordance between bronchial hyperresponsiveness, fractional exhaled nitric oxide, and asthma control in children. Pediatr Pulmonol. 2016;51(10):1004-9.

17. Waibel $\mathrm{V}$, Ulmer $\mathrm{H}$, Horak E. Assessing asthma control: symptom scores, GINA levels of asthma control, lung function, and exhaled nitric oxide. Pediatr Pulmonol. 2012;47(2):113-8.

\section{Publisher's Note}

Springer Nature remains neutral with regard to jurisdictional claims in published maps and institutional affiliations.

\section{Ready to submit your research? Choose BMC and benefit from:}

- fast, convenient online submission

- thorough peer review by experienced researchers in your field

- rapid publication on acceptance

- support for research data, including large and complex data types

- gold Open Access which fosters wider collaboration and increased citations

- maximum visibility for your research: over $100 \mathrm{M}$ website views per year

At BMC, research is always in progress.

Learn more biomedcentral.com/submissions 